Pacific Journal of Mathematics

HOMOMORPHISMS OF BANACH ALGEBRAS WITH MINIMAL 


\title{
HOMOMORPHISMS OF BANACH ALGEBRAS WITH MINIMAL IDEALS
}

\author{
GREgory F. BACHELIS
}

\begin{abstract}
Let $A$ be a semi-simple Banach algebra with socle $F$, and let $\nu$ be a homomorphism of $A$ into a Banach algebra. It is shown that if $I$ is a minimal one-sided ideal of $A$, then the restriction of $\nu$ to $I$ is continuous. This is then used to deduce continuity properties of the restriction of $\nu$ to $F$. In particular, if $F$ has a bounded left or right approximate identity, then $\nu$ is continuous on $F$.
\end{abstract}

In [1] and [2] we deduced continuity properties of $\nu \mid F$ in case $A$ was a semi-simple annihilator Banach algebra. In this paper we obtain essentially the same results, but without the hypothesis that $A$ be an annihilator algebra.

We first show that the restriction of $\nu$ to any minimal one-sided ideal is continuous. The proof is almost purely algebraic. We then show that there exists a constant $K$ such that

$$
\|\nu(x y)\| \leqq K\|x\|\|y\|, \quad x \in F, \quad y \in \bar{F} .
$$

As a corollary we obtain that $\nu \mid F$ is continuous if $F$ has a bounded left or right approximate identity.

1. Preliminaries. Throughout this section we assume that $A$ is a complex semi-simple Banach algebra. The socle, $F$, is defined to be the sum of the minimal right ideals. An idempotent $e$ is called minimal if $e A$ is a minimal right ideal. We use without reference the basic facts about the socle of a Banach algebra (see e.g. [7, pp. 45-47]).

The following two lemmas, together with the "Main Boundedness Theorem" of Bade and Curtis ([3, Thm. 2.1], [2, Thm. 4.1]) are the basic ingredients in the proofs that follow. The first lemma is due essentially to Barnes.

Lemma 1.1. Let $\left\{x_{1}, \cdots, x_{n}\right\} \subset F$. Then there exist idempotents $e$ and $f$ in $F$ such that $\left\{x_{1}, \cdots, x_{n}\right\} \subset e A f$ and $e A f$ is finite-dimensional.

Proof. By hypothesis, there exist minimal right ideals, $I_{1}, \cdots, I_{m}$, whose sum contains $\left\{x_{1}, \cdots, x_{n}\right\}$. By [4, Thm. 2.2], there exists an idempotent $e \in F$ such that $e A=I_{1}+\cdots+I_{m}$. Thus $x_{k} \in e A, 1 \leqq k \leqq n$. 
Similarly, there exists an idempotent $f \in F$ such that $x_{k} \in A f, 1 \leqq k \leqq n$. Hence $x_{k}=e x_{k} f \in e A f, 1 \leqq k \leqq n$.

If $u$ and $v$ are minimal idempotents, and $u A v \neq(0)$, then $u A v$ is one-dimensional [9, Lemma 5.1]. Since $e$ and $f$ are each the sum of minimal idempotents, $e A f$ is finite-dimensional.

Lemma 1.2. Let $e$ be a minimal idempotent and suppose that $e A$ is infinite-dimensional. Then there exists a sequence of minimal idempotents $\left\{g_{n}\right\}$ such that $g_{n} g_{m}=0, n \neq m$, and $e A g_{n} \neq(0)$ for all $n$.

Proof. Let $g_{1}=e$. Assume that $g_{1}, \cdots, g_{n}$ have been chosen with the desired properties. Let $f=g_{1}+\cdots+g_{n}$. Then $f=f^{2}$ and $e A f$ is finite-dimensional. Thus there exists $x \in e A$ such that $x(1-f) \neq 0$. Since $e A$ is a minimal right ideal, there exists $w \in A$ such that $x(1-f) w=e$. Let $g_{n+1}=(1-f)$ wex $(1-f)$. Then $f g_{n+1}=$ $g_{n+1} f=0$, so $g_{k} g_{n+1}=g_{n+1} g_{k}=0,1 \leqq k \leqq n$. Also

$$
\begin{aligned}
g_{n+1}^{2} & =(1-f) \text { wex }(1-f)(1-f) \text { wex }(1-f) \\
& =(1-f) \text { wex }(1-f) \text { wex }(1-f) \\
& =(1-f) \text { wex }(1-f) \\
& =g_{n+1} .
\end{aligned}
$$

Since $e$ is minimal, $g_{n+1}$ is as well. Since

$$
\operatorname{exg}_{n+1}=e x(1-f)=x(1-f) \neq 0,
$$

$e A g_{n+1} \neq(0)$. The conclusion follows by induction.

NotE. Lemma 1.2 above takes the place of [2, Lemma 2.2] in what follows. Evidently the latter does not hold in this more general situation, since the norm induced in $e A$ as a subset of $(A e)^{*}$ (the set of bounded linear functionals on $A e$ ) need not be equivalent to the given norm on $e A$ (see Remark 2.5).

2. The main results. Throught this section we assume that $A$ is a complex semi-simple Banach algebra with socle $F$ and that $\nu$ is a homomorphism of $A$ into a Banach algebra. We first show the following.

THEOREM 2.1. If $I$ is a minimal one-sided ideal, then $\nu \mid I$ is continuous.

Proof. Suppose that $I$ is a minimal right ideal. Then there exists a minimal idempotent $e$ such that $I=e A$. 
Let $J=\{x \in A \mid y \rightarrow \nu(x y)$ is continuous on $A\}$. Then one verifies that $J$ is a two-sided ideal in $A$ [8, p. 153], and that an idempotent $g$ is in $J$ if and only if $\nu \mid g A$ is continuous.

We may assume $e A$ is infinite-dimensional, since otherwise the conclusion trivially follows. Choose $\left\{g_{n}\right\}$ as given by Lemma 1.2. If $g_{n} \in J$ then there exists $x_{n} \in g_{n} A$ such that $\left\|x_{n}\right\|=1$ and $\left\|\boldsymbol{\nu}\left(x_{n}\right)\right\|>$ $n\left\|g_{n}\right\|$. Since $g_{n} x_{n}=x_{n}$ and $g_{m} x_{n}=g_{m} g_{n} x_{n}=0, m \neq n$, the Main Boundedness Theorem [2, Thm. 4.1] implies that $g_{n} \in J$ for some $n$. Since $e A g_{n} \neq(0)$ and $J$ is a left ideal, we have that $e A \cap J \neq(0)$. But $J$ is a right ideal and $e A$ is a minimal right ideal. Thus $e \in e A \subset J$, and $\nu \mid e A$ is continuous.

REMARK 2.2. (cf. [3, p. 597]) If $I=e A$ is an infinite-dimensional minimal right ideal, then it is always possible to construct a discontinuous homomorphism $\nu$ of $e A$ into a Banach algebra. For let $\phi$ be a discontinuous linear functional on $e A$, and define

$$
\|x\|_{1}=\|x\|+|\phi(x)|,
$$

If $x \in e A$, then $x e=\lambda e, \lambda$ complex. Thus

$$
x^{n}=(x e)^{n-1} x=\lambda^{n-1} x,
$$

so

$$
\left\|x^{n}\right\|^{1 / n}=|\lambda|^{(n-1) / n} \|\left. x\right|^{1 / n} .
$$

Hence $|\lambda|=\rho(x)$, the spectral radius of $x$.

If $x, y \in A$, then

$$
\begin{aligned}
\|x y\|_{1} & =\|x y\|+|\phi(x y)| \\
& \leqq\|x\|\|y\|+|\phi(x e y)| \\
& \leqq\|x\|\|y\|+\rho(x) \mid \phi(y) \\
& \leqq\|x\|(\|y\|+|\phi(y)|) \\
& \leqq\|x\|_{1}\|y\|_{1},
\end{aligned}
$$

so $\|\cdot\|_{2}$ is a normed algebra norm on $e A$.

Now let $B$ be the completion of $e A$ in this norm and define $\nu: e A \rightarrow B$ by $\nu(x)=x$. Then $\nu$ is a discontinuous homomorphism of $e A$. By the above theorem, $\nu$ does not extend to a homomorphism of $A$.

We now have:

THEOREM 2.3. Let $A$ be a semi-simple Banach algebra with socle $F$ and let $\nu$ be a homomorphism of $A$ into a Banach algebra. Then there exists a constant $K$ such that 


$$
\|\nu(x y)\| \leqq K\|x\|\|y\| \quad x \in F, \quad y \in \bar{F}
$$

Proof. Since $F$ is the sum of the minimal right ideals and also the sum of the minimal left ideals, it follows from Theorem 2.1 that, for any $x \in F$, the mappings $y \rightarrow \nu(x y)$ and $y \rightarrow \nu(y x)$ are continuous on $A$. Thus it suffices to show that

$$
\sup _{x, y \in F} \frac{\|\nu(x y)\|}{\|x\|\|y\|}<\infty .
$$

In addition, if $e=e^{2} \in F$, then $\nu \mid e A$ and $\nu \mid A e$ are continuous. With these observations, the proof is virtually the same as that of [2, Thm. 4.5], with [2, Lemma 2.1] replaced by Lemma 1.1.

COROLlaRY 2.4. If $F$ has a bounded left or right approximate identity, then $\nu$ is continuous on $F$.

Proof. If $F$ has a bounded left or right approximate identity, then of course so does $\bar{F}$. The proof now follows as that of [2, Cor. 4.9], with [1, Cor. 4.9] replaced by Lemma 1.1 .

REMARK 2.5. Let $X$ and $Y$ be Banach spaces with $Y \subset X$ and such that the inclusion map $i: Y \rightarrow X$ is continuous and $i(Y)^{-}=X$. Let $B(X, Y)$ denote the bounded operators from $X$ to $Y$ and let $B^{\prime}(X, Y)$ denote the compact operators from $X$ to $Y$. Then $B(X, Y)$ is a semi-simple Banach algebra with $B^{\prime}(X, Y)$ as a closed two-sided ideal. If $A$ is a closed two-sided ideal of $B(X, Y)$ containing $B^{\prime}(X, Y)$, then $A$ is semi-simple with socle $F$ consisting of those bounded operators from $X$ to $Y$ with finite-dimensional range. Each minimal right ideal of $A$ is linearly homeomorphic to $X^{*}$ and each minimal left ideal is linearly homeomorphic to $Y$. Now $i^{*}: Y^{*} \rightarrow X^{*}$ is one-to-one and continuous, but not bi-continuous if $Y \neq X$.

If $X=Y$ and satisfies the metric approximation property [5, p. 178], then $F$ has a bounded left approximate identity, so the above corollary applies to $A$. If in addition $X$ has a continued bisection, then Johnson [6, Thm. 3.5] has shown that any homomorphism of $A$ into a Banach algebra is continuous on $B^{\prime}(X, X)(=\bar{F})$. $\mathrm{He}$ has also shown that any homomorphism of $B(X, X)$ into a Banach algebra is continuous if $X$ has a continued bisection [6, Thm. 3.3].

\section{REFERENCES}

1. G. F. Bachelis, Homomorphisms of annihilator Banach algebras, Pacific J. Math., 25 (1968), 229-247.

2. - Homomorphisms of annihilator Banach algebras, II, Pacific J. Math., 30 (1969) 283-291. 
3. W. G. Bade and P. C. Curtis, Jr., Homomorphisms of commutative Banach algebras, Amer. J. Math., 82 (1960), 589-608.

4. B. A. Barnes, A generalized Fredholm theory for certain maps in the regular representations of an algebra, Canad. J. Math., 20 (1968), 495-504.

5. A. Grothendieck, Produits tensoriels topologiques et espaces nucléaires, Mem. Amer. Math. Soc., No. 16 (1955).

6. B. E. Johnson, Continuity of homomorphisms of algebras of operators, J. London Math. Soc., 42 (1967), 537-541.

7. C. E. Rickart, General Theory of Banach Algebras, Van Nostrand, New York, 1960.

8. J. D. Stein, Jr., Continuity of homomorphisms of von Neumann algebras, Amer.

J. Math., 91 (1969), 153-159.

9. B. Yood, Faithful *-representations of normed algebras, Pacific J. Math., 10 (1960), 345-363.

Received May 20, 1971. The author would like to thank Professor Forrest Miller for helpful discussions.

Kansas State University 



\section{PACIFIC JOURNAL OF MATHEMATICS}

\section{EDITORS}

\author{
H. SAMELSON \\ Stanford University \\ Stanford, California 94305

\section{R. HoвBY} \\ University of Washington \\ Seattle, Washington 98105
}

\section{J. DugundJI}

Department of Mathematics University of Southern California Los Angeles, California 90007

\author{
RichaRd ARENS \\ University of California \\ Los Angeles, California 90024
}

\section{ASSOCIATE EDITORS}
E. F. BECKENBACH
B. H. NEUMANN
F. WOLF
K. YoshidA

\section{SUPPORTING INSTITUTIONS}

\author{
UNIVERSITY OF BRITISH COLUMBIA \\ CALIFORNIA INSTITUTE OF TECHNOLOGY \\ UNIVERSITY OF CALIFORNIA \\ MONTANA STATE UNIVERSITY \\ UNIVERSITY OF NEVADA \\ NEW MEXICO STATE UNIVERSITY \\ OREGON STATE UNIVERSITY \\ UNIVERSITY OF OREGON \\ OSAKA UNIVERSITY
}

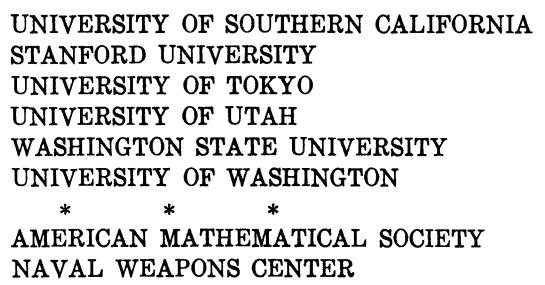

The Supporting Institutions listed above contribute to the cost of publication of this Journal, but they are not owners or publishers and have no responsibility for its content or policies.

Mathematical papers intended for publication in the Pacific Journal of Mathematics should be in typed form or offset-reproduced, (not dittoed), double spaced with large margins. Underline Greek letters in red, German in green, and script in blue. The first paragraph or two must be capable of being used separately as a synopsis of the entire paper. The editorial "we" must not be used in the synopsis, and items of the bibliography should not be cited there unless absolutely necessary, in which case they must be identified by author and Journal, rather than by item number. Manuscripts, in dup icate if possible, may be sent to any one of the four editors. Please classify according to the scheme of Math. Rev. Index to Vol. 39. All other communications to the editors should be addressed to the managing editor, Richard Arens, University of California, Los Angeles, California, 90024.

50 reprints are provided free for each article; additional copies may be obtained at cost in multiples of 50 .

The Pacific Journal of Mathematics is published monthly. Effective with Volume 16 the price per volume (3 numbers) is $\$ 8.00$; single issues, $\$ 3.00$. Special price for current issues to individual faculty members of supporting institutions and to individual members of the American Mathematical Society: $\$ 4.00$ per volume; single issues $\$ 1.50$. Back numbers are available.

Subscriptions, orders for back numbers, and changes of address should be sent to Pacific Journal of Mathematics, 103 Highland Boulevard, Berkeley, California, 94708.

PUBLISHED BY PACIFIC JOURNAL OF MATHEMATICS, A NON-PROFIT CORPORATION

Printed at Kokusai Bunken Insatsusha (International Academic Printing Co., Ltd.), 270, 3-chome Totsuka-cho, Shinjuku-ku, Tokyo 160, Japan. 


\section{Pacific Journal of Mathematics}

\section{Vol. 41, No. 2 December, 1972}

Tom M. (Mike) Apostol, Arithmetical properties of generalized Ramanujan sums .......................................... 281

David Lee Armacost and William Louis Armacost, On p-thetic groups ........ 295

Janet E. Mills, Regular semigroups which are extensions of groups .......... 303

Gregory Frank Bachelis, Homomorphisms of Banach algebras with minimal ideals ................................................ 307

John Allen Beachy, A generalization of injectivity .................. 313

David Geoffrey Cantor, On arithmetic properties of the Taylor series of rational functions. II.........................................

Václáv Chvátal and Frank Harary, Generalized Ramsey theory for graphs. III.

Small off-diagonal numbers .................................. 335

Frank Rimi DeMeyer, Irreducible characters and solvability of finite groups . . . . 347

Robert P. Dickinson, On right zero unions of commutative semigroups........ 355

John Dustin Donald, Non-openness and non-equidimensionality in algebraic

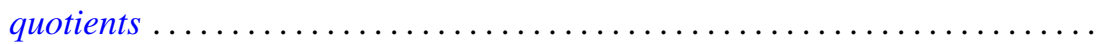

John D. Donaldson and Qazi Ibadur Rahman, Inequalities for polynomials with a prescribed zero ........................................ 375

Robert E. Hall, The translational hull of an $N$-semigroup ................ 379

John P. Holmes, Differentiable power-associative groupoids.............. 391

Steven Kenyon Ingram, Continuous dependence on parameters and boundary data for nonlinear two-point boundary value problems .

Robert Clarke James, Super-reflexive spaces with bases ..........

Gary Douglas Jones, The embedding of homeomorphisms of the plane in

continuous flows...............................

Mary Joel Jordan, Period $H$-semigroups and $t$-semisimple periodic

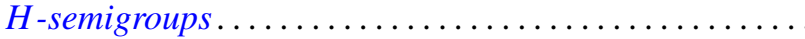

Ronald Allen Knight, Dynamical systems of characteristic 0

Kwangil Koh, On a representation of a strongly harmonic ring by sheaves...

Hui-Hsiung Kuo, Stochastic integrals in abstract Wiener space. ..

Thomas Graham McLaughlin, Supersimple sets and the problem of extending a

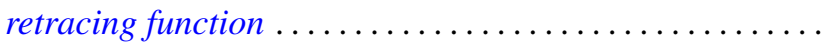

William Nathan, Open mappings on 2-manifolds .

M. J. O'Malley, Isomorphic power series rings

Sean B. O'Reilly, Completely adequate neighborhood systems and metrization

Qazi Ibadur Rahman, On the zeros of a polynomial and its derivative...

Russell Daniel Rupp, Jr., The Weierstrass excess function ..

Hugo Teufel, A note on second order differential inequalities and functional

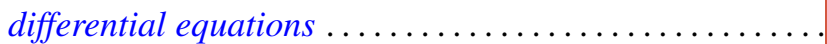

M. J. Wicks, A general solution of binary homogeneous equations over free 